\title{
Pengalaman Keluarga Merawat Penderita Kusta dalam Menghadapi Stigma Masyarakat di Kelurahan Limo Depok - Jawa Barat
}

\author{
Tatiana Siregar ${ }^{1}$, Diah Ratnawati ${ }^{2}$ \\ ${ }^{1,2}$ Fakultas Ilmu Kesehatan, UPN "Veteran" Jakarta \\ E-mail: tatiana_siregar@yahoo.co.id
}

\begin{abstract}
Abstrak
Penyakit kusta dapat menimbulkan masalah yang sangat kompleks, masalah yang dimaksud bukan hanya dari segi medis tetapi meluas sampai masalah sosial, ekonomi, psikologis, budaya, keamanan dan ketahanan nasional (Depkes RI, 2005). Gambaran tubuh penderita kusta yang mengerikan adalah alasan utama terjadi stigma sosial. Penderita kusta yang cacat tidak mampu bekerja dan mereka kehilangan pekerjaan mereka dan kemandirian ekonomi mereka. Selain itu, mereka kehilangan harga diri dan kualitas hidup sebagai akibat stigma. Tujuan penelitian ini adalah untuk mencari informasi tentang "Pengalaman Keluarga Merawat Penderita Kusta Dalam Menghadapi Stigma Masyarakat Di Kelurahan Limo Depok - Jawa Barat". Penelitian ini merupakan penelitian deskritif kualitatif dengan menggunakan analisa metode Colaizzi, yang dilakukan pada sembilan partisipan pada bulan Februari - Agustus 2017. Hasil analisis menunjukkan ada tiga tema utama yaitu pemahaman keluarga terhadap perawatan kusta,pengalaman keluarga penderita kusta dalam menghadapi stigma,dan pandangan terhadap stigma yang dihadapi karena ada anggota keluarga menderita kusta. Keluarga menjaga anggota keluarga yang menderita kusta dari stigma masyarakat dengan menutupi kondisi kesehatan tersebut. Masalah atau hambatan yang dialami keluarga dalam menghadapi stigma dari masyarakat ketika penderita mengalami perasaan sedih dan menyendiri. Keluarga berharap agar mendapatkan penyuluhan kesehatan dalam mencegah kecacatan pada penderita kusta. Hasil penelitian ini dapat menjadi acuan pelayanan kesehatan, keluarga dan pemerintah dalam mengeluarkan kebijakan untuk mengeliminasi penyakit kusta di Indonesia.
\end{abstract}

Kata Kunci: Colaizzi; Kusta; Stigma

Rujukan artikel penelitian:

Siregar, T., Ratnawati, D. (2018). Pengalaman Keluarga Merawat Penderita Kusta dalam Menghadapi Stigma Masyarakat di Lelurahan Limo Depok - Jawa Barat. Jurnal Ilmiah Keperawatan Indonesia. Vol. 1 (2): 63-82 


\title{
The Quality of Life of the Leppers Family in Facing the Social Stigma in Limo Depok - Jawa Barat
}

\begin{abstract}
Leprosy can cause an extremely complex problems. The problem not just from medical side but can be broader to social, economic, psychologycal, cultureal, and also security and defense problem (DepKes RI, 2005). Horrible image of leppers is the main reason why social stigma happened. Leppers can not work and they lost their jobs and their economic independency. Other than that, they also lost their self esteem and their quality of life as a result of the stigma. The purpose of this research is to find information about "The Quality of Life of the Leppers Family in Facing the Social Stigma in Limo Depok - Jawa Barat". This research is a Qualitative Descriptive research using Colaizzi method that done on nine participants in February until August 2017. Result of the analysis show that there are three main themes which are family understanding on Leprosy treatment, experience of the leppers family in facing the social stigma, and view of the facing stigma because of there is a family member that is a lepper. Family treat their family member that is a Lepper from the social stigma by covering that health issue. The problem or impedement that the family experiencing in facing the social stigma when the lepper feel sad and lonely. The family hopes to get a health counseling in prevent disability on Leppers. The result of this research can be a reference of health treatment, family and government on issuing policy to eliminate Leprosy in Indonesia.
\end{abstract}

Keywords: Colaizzi; Leprosy; Stigma

\section{PENDAHULUAN}

Masalah kesehatan di Indonesia merupakan bagian integral dari masalah bangsa Indonesia. Termasuk masalah kesehatan di Indonesia salah satunya adalah penyakit menular yaitu kusta. Penyakit kusta atau lepra masih merupakan masalah kesehatan di Indonesia, karena permasalahan yang kompleks yaitu berdampak pada peningkatan kejadian cacat, morbiditas, dan stigma sosial yang negatif di masyarakat. Kusta adalah penyakit yang disebabkan oleh infeksi Mycrobacterium leprae, yang menyerang bagian tubuh diantaranya saraf dan kulit. Penyakit ini adalah tipe penyakit granulomatosa pada saraf tepi dan mukosa dari saluran pernafasan atas dan lesi pada kulit .(Infodatin Kemenkes, 2015). 
Kota Depok merupakan Kota dari Provinsi Jawa Barat. Berdasarkan data dari profil kesehatan Kota Depok tahun 2013 di informasikan bahwa: " hasil evaluasi program P2P kusta menunjukan bahwa pada tahun 2013 penderita kusta PB sebanyak 3 orang, penderita MB sebanyak 49 orang jadi total penderita kusta PB/MB sebanyak 52 orang"

Kelurahan Limo merupakan bagian dari wilayah Kota Depok. Berdasarkan studi pendahuluan di kelurahan Limo dalam bentuk survey pada bulan Januari 2016 didapatkan data bahwa ditemukan ada 8 orang yang menderita kusta, dengan kehidupan ekonomi digaris kemiskinan, dan belum maksimalnya penderita kusta menjalankan pengobatan dan perawatan, hal ini dikarenakan kurangnya pengetahuan keluarga mengenai informasi tentang penyakit kusta, serta merasa malu memiliki anggota keluarga dengan penyakit kusta, karena stigma negaitf dari masyarakat luar tentang penyakit kusta.

Oleh karena itu, dalam upaya menghilangkan stigma dan diskriminasi, dibutuhkan motivasi dan komitmen yang kuat baik dari penderita maupun masyarakat. Penderita dan keluarga diharapkan dapat mengubah pola pikirnya, sehingga dapat berdaya untuk menolong diri mereka sendiri, bahkan orang lain..

\section{METODE}

Penelitian yang dilakukan ini menggunakan desain penelitian fenomenologi dari kualitatif. Populasi yang digunakan dalam penelitian ini adalah warga yang bertempat tinggal di wilayah Kelurahan Limo. Penentuan partisipan dengan serangkaian kriteria untuk mewakili fenomena yang diteliti dari pengalaman individu. Partisipan dalam penelitian yang dilakukan ini mempunyai kriteria inklusi meliputi: (1) keluarga yang memiliki anggota sebagai penderita Kusta; (2) mampu berkomunikasi secara baik dengan bahasa Indonesia; (3) bertempat tinggal di wilayah Kelurahan Limo Depok; (4) bersedia menjadi partisipan dan menandatangani informed consent. Penelitian ini menggunakan 9 partisipan. 
Cara pengumpulan data pada penelitian yang dilakukan ini lebih menekankan pada teknik wawancara, khususnya wawancara mendalam (depth interview) dan observasi partisipan.

Alat pengumpulan data yang utama atau instrumen dalam penelitian ini adalah peneliti sendiri. Data diperoleh dengan menyediakan alat pendukung seperti kamera, IC recorder atau MP4, alat tulis dan kertas (sebelumnya diuji coba dengan melatih anggota peneliti melakukan wawancara). Analisa hasil wawancara dengan partisipan menggunakan langkah-langkah menggunakan strategi Colaizzi (1978) seperti yang dikutip Sanders (2003), Peziale dan Carpenter, 2007 dalam Shosha (2012)

\section{HASIL DAN PEMBAHASAN}

Partisipan dalam penelitian ini adalah keluarga yang memiliki anggota keluarganya menderita penyakit kusta. Jumlah partisipan yang didapat peneliti sebanyak 9 orang dan berada di Kelurahan Limo, Kota Depok, Jawa Barat. Pengambilan data dilakukan pada Februari sampai dengan Agustus 2017. Sebanyak 9 partisipan dengan karakteristik sebagai berikut: berjenis kelamin wanita sebanyak 7 orang $(77,8 \%)$, usia direntang 26 - 35 tahun sebanyak 2 orang (22,2\%), pendidikan partisipan terbanyak SMP ada 4 orang (44,4\%), jenis pekerjaan terbanyak tidak bekerja sebanyak 7 orang $(77,8 \%)$, hubungan masih satu keluarga dengan penderita kusta sebanyak 8 orang $(88,9 \%)$ dan 1 orang adalah sebagai majikan. Hasil transkrip data menggambarkan 3 tema utama, yaitu: pemahaman terhadap perawatan kusta, pengalaman keluarga dengan penderita kusta, dan pandangan terhadap stigma yang dihadapi karena ada anggota keluarga yang menderita kusta.

\section{Pemahaman terhadap perawatan kusta}

Partisipan menjawab 10 sub tema dalam menjawab tema utama ini, kesembilan partisipan mengatakan tidak tahu apa itu kusta dan bagaiamana perawatan dan pencegahannya. 
Kusta adalah penyakit kulit yang harus diasingkan oleh orangorang,penularannya dari darah” (P8).

“...tidak mengerti bagaiamana pencegahan penayakit kusta” (P5)

"penyakit kusta adalah penyakit kulit biasa tidak memerlukan perawatan khusus." (P4)

Satu partisipan sama sekali tidak mengetahui kecacatan akibat penyakit kusta:

“tidak mengetahui dampak dari penyakit kusta” (P5)

Enam partisipan mengemukakan suasana hatinya dengan ada anggota keluarga yang menderita kusta menyatakan kaget.

"saat pertama istri saya ke Puskesmas dibilang penyakit kusta, saya dan istri shock, galau, dan takut orang-orang menjauhi istri/keluarga saya” (P4)

Sembilan partisipan mengungkapkan melakukan berbagai upaya yang berguna untuk anggota keluarganya.

“...segala usaha yang dilakukan pasti akan membuahkan hasil, terbukti 2 adik laki-laki aku yang sempat mengalami penyakit kusta dan saat ini sudah dinyatakan sembuh tetapi ya belum kembali untuk cek lab dan lainnya untuk memastikan"(P9)

Kesembilan partisipan mengungkapkan mampu mengontrol dalam minum obat dan perawatan pencegahan kecacatan bagi anggota keluarganya yang menderita kusta.

“ ya, selalu membawa pembantu saya ke Puskesmas setiap bulannya untuk ambil

obat, Terus selalu saya itu mengingatkan mandi sehari 2 kali dan berjemur" (P6)

Kedelapan partisipan mengatakan bahwa setelah didiagnosis penyakit kusta, menurunnya kualitas hidup pada penderita.

“....saat ibu menderita kustanya saya merasakan satu persatu keluarga mulai menjauh, saat ada acara keluarga pun ibu merasa diasingkan, ..........merasa terpukul ...ikut merasakan kesedihan yang dialami oleh ibu. keluarga yang dulunya sering main ke rumah, namun saat ini sudah tidak lagi... ibu yang http://www.jurnal.umt.ac.id/index.php.jik 
dulunya sering keluar rumah, saat ini ibu lebih banyak menghabiskan waktu di dalam rumah saja dan keluar hanya di pagi hari jam 06.00 pagi untuk membeli sayuran untuk di masak, setelah itu ibu hanya di rumah saja meskipun sesekali pergi keluar tapi ya itu jarang" (P9)

Kesembilan partisipan mengatakan perlunya penjelasan atau penyuluhan dari petugas kesehatan tentang penyakit kusta:

"Seharusnya petugas kesehatan memberikan penjelasan kepada kami para keluarga penderita agar mengerti bahwa kusta ini sebenarnya adalah iniloh. Terutama menjelaskan bagaimana pencegahan agar tidak menular. Selain itu bisa memberikan penyuluhan kesehatan di area tempat tinggal kami, sehingga seluruh warga bisa memahami bagaimana penyakit kusta itu, mulai dari penyebab, pencegahan, perawatan dan perjalanan penyakit sebenarnya" (P9)

Menurut (Setiadi, 2008) peran keluarga menggambarkan seperangkat perilaku interpersonal, sifat, kegiatan yang berhubungan dengan individu dalam posisi dan situasi tertentu. Peranan individu dalam keluarga didasari oleh harapan dan pola perilaku dari keluarga, kelompok dan masyarakat Peneliti Semrittirong (2014) juga menyampaikan tentang pengetahuan terhadap kusta, ia melakukan penelitian kepada 19 orang penderita kusta, tidak satupun responden mengetahui penyebab penyakit kusta kecuali responden petugas kesehatan.

Menurut Notoatmdjo (2007): pengetahuan atau kognitif merupakan domain yang sangat penting untuk terbentuknya suatu tindakan seseorang (overt behaviour). Sobrinho et al. (2007) menyatakan pentingnya pendidikan kesehatan untuk mencegah cacat dan untuk merangsang kontrol diri. Das (2006) mengemukakan rendahnya pengetahuan tentang penyakit kusta, mengakibatkan penderita kusta tidak mengetahui akibat buruk yang ditimbulkan oleh penyakit kusta seperti cacat fisik. Maka disimpulkan pengetahuan dan pemahaman tentang penyakit kusta sangat penting bagi keluarga maupun penderita kusta karena, akan mempengaruhi proses kesembuhan penyakit dan terhindarnya kecacatan lebih lanjut akibat dari penyakit kusta. 


\section{Pengalaman keluarga dengan penderita Kusta dalam menghadapi stigma masyarakat}

1. Kesembilan partisipan mengatakan proses perawatan dalam pencegahan kecacatan pada anggota keluarga dengan kusta adalah dengan mematuhi minum obat yang diberikan dari Puskesmas.

“...selalu rutin membawa pembantu saya itu ya ke Puskesmas untuk mengambil obat yang sudah dijadwalkan oleh Puskesmas, mengontrol untuk minum obat jangan sampai putus. Selalu mengingatkan untuk berjemur pada pagi hari tapi ya itu tidak mau terkena sinar matahari pagi dengan alasan panas. Semua alat mandi selalu dipisah baik sabun, handuk dan pakaian” (P6)

2. Rata-rata keluarga sudah merawat penderita kusta selama 8 bulan.

“Anakku telah menjalani pengobatan \pm 2 bulan sejak 12 Juni 2017. Hmmm...tapi sudah dua minggu ini tidak minum lagi karena anak aku merasa gatal-gatal makin jadi, dan beruntusan merah-merah, akhirnya ke dokter klinik dekat rumah, dikasih obat dan salep sembuh gatal-gatalnya, nanti minggu depan mau ke Puskesmas lagi” (P1)

3. Empat partisipan mengatakan tidak ada materi yang disampaikan oleh petugas kesehatan dalam mencegah kecacatan, petugas hanya fokus pada penggunaan obat.

“. .hanya dinformasikan untuk minum obat secara rutin dan pengambilan obat di Puskesmas”(P7)

4. Pengalaman keluarga dalam menghadapi stigma pada anggota keluarga yang menderita kusta.

"Selama satu tahun mamah menderita kusta selama itu juga pandangan masyarakat dan keluarga merasa takut untuk berkomunikasi dengan mamah, sejak itupun banyak sekali perubahan pada kehidupan mamah http://www.jurnal.umt.ac.id/index.php.jik 
yang lebih sering di rumah. Sampai waktu itu keluarga merasa drop karena omongan tetangga yang ini itu bahwa penyakit kusta harus dijauhi penderitanya" (P9)

5. Rata-rata lama mendapat stigma

"...sudah lama sich 8 bulanan ini diperlakukan seperti itu ya dijauhi..." (P6)

6. Enam partisipan awal keluarga didiagnosa kusta adalah sedih dan khawatir.

"Merasa kaget, sedih, dan khawatir bahwa penyakt anaknya berbahaya yang dapat menyebabkan lepasnya jari-jari tangan satu persatu seperti sakit kusta yang dialami tetangganya" (P2)

7. Keluarga menjaga anggota keluarga yang menderita kusta dari stigma

"Saat awal terkena kusta, suami merasa dijauhi oleh rekan-rekan kerjanya dan merasa diasingkan di lingkungan kerja. Sehingga suami memutuskan untuk keluar kerja. Perasaan saya dan suami sedih" (P8)

8. Perubahan yang terjadi akibat stigma:

"Banyak sekali perubahan yang tadinya ramah banyak keluarga datang setiap minggu atau bulannya, namun saat mamah menderita kusta justru dijauhi. Mamah lebih banyak di rumah" (P9)

9. Cara menjaga keluarga tekena stigma.

"Tidak menceritakan kondisi kesehatan istrinya dari kepada siapaun" (P7)

10. Keluarga mengalami kesulitan dalam menghadapi stigma:

"Banyak yang mengkritik tentang kesehatan suami saya" (P8)

11. Kondisi kontak dengan orang lain dalam menghadapu stigma:

"Selama istri saya menderita kusta istri saya jadi jarang keluar rumah dan berkomunikasi dengan warga sekitar" (P4)

12. Enam partisipan belum pernah mendapat penjelasan dan bimbingan dari perawat tentang pencegahan kecacatan dalam menghilangkan stigma masyarakat.

"Tidak ada penjelasan dan penyuluhan tentang penyakit yang diderita hanya ada

http://www.jurnal.umt.ac.id/index.php.jik 
pendataan saja” (P8)

13. Hampir separuh dari jumlah partisipan, lima partisipan menyatakan menjadi lebih khawatir ketika mendapat penjelasan dan bimbingan dari perawat tentang pencegahan kecacatan dalam menghilangkan stigma masyarakat.

"Setelah mendapat penjelasan tentang penyakit ibunya keluarga menjadi khawatir dan menyarankan ibunya yang menderita kusta untuk kembali ke Puskesmas dan meminum obat kembali” (P1)

14. Terdapat enam partisipan menyatakan mendapat stigma dari masayarakat Frekuensi mendapatkan stigma karena ada anggota keluarga yang menderita kusta.

"Sangat sering dan setiap hari” (P9)

Perlakuan yang diberikan sebagai akibat stigma karena ada anggota keluarga yang menderita kusta

"Jika dicemoohkan maka keluarga tidak akan membalas cemoohan"

Upaya yang dilakukan dalam menghadapi stigma karaena ada anggota keluarga yang menderita kusta.

"Saya membatasi pertemuan dengan orang lain" (P4)

Perasaan- perasaan saat menghadapi stigma karena ada anggota keluarga yang menderita kusta.

"Tentunya sangat sedih dan terpukul saat mendengar dan melihat perlakuan orang -orang yang mencemooh dan menjauhi mamah"

a. Percaya diri selama menghadapi stigma karena ada anggota keluarga yang menderita

kusta.

"Tidak peduli omongan orang lain dan selalu percaya diri" (P8)

b. Meningkatnya kemampuan keluarga dalam menghadapi stigma karena ada anggota keluarga yang menderita kusta. 
"Apa yang dilakukan untuk perawatan kusta seperti mengontrol minum obat sudah maksimal dan bertekad mengaobai anaknya sampai sembuh" (P2)

c. Faktor-faktor yang mempengaruh kepercayaan/ keyakinan dan kemampuan di keluarga selama menghadapi stigma karena ada anggota keluarga yang menderita kusta.

Faktor internal:

"keinginan yang besar dari istri karena takut menular kepada anaknya"(P4)

Faktor eksternal:

"dukungan keluarga untuk istri yang terus memotivasi agar proses pengobatan berjalan dengan baik" (P7)

d. Situasi dan tanggapan teman-teman saat tahu bahwa ada anggota keluarga yang menderita kusta.

"teman-teman kerja suami saya menjauhinya karena takut tertular" (P8)

15.Perilaku yang dialami dalam menghadapi stigma:

a. Teman-teman menjauh "ya...itu dijauhi ya ketika mau diajak ngobrol ..." (P9)

b. Kekhawatiran masyarakat jika ada keluarga yang anggota keluarganya menderita kusta

"Masyarakat sekitar merasa khawatir bahwa penyakit yang diderita anaknya dapat menular" (P2)

c. Kurang jujur terhadap masalah yang dialami terkait stigma karena ada anggota keluarga yang menderita kusta

"Saya membenarkan bahwa istri saya menderita alergi, tidak memberitahu yang sebenarnya dan dengan mengurangi pertemuan dengan masyarakat" (P4) 
d. Solusi yang diberikan oleh petugas kesehatan terutama perawat dalam menghadapi stigma karena ada anggota keluarga yang menderita kusta.

"Petugas kesehatan bilang jangan takut penyakit ini akan sembuh jika rutin mengkonsumsi obat" (P4).

Kondisi/situasi keluarga saat sekarang ini

"untuk saat ini sudah biasa saja dan menjalani hidup seperti biasanya meskipun sudah jarang berinteraksi dnegan orang lain” (P9)

Berdasarkan sembilan partisipan, tiga keluarga yang tidak mengalami stigma dari masyarakat, tiga keluarga menyembunyikan penyakit kusta yang didertia oleh anggota keuarganya karena khawatir, takut, dicemooh dan dijauhi masyarakat, dan tiga keluarga menyatakan mengalami stigma masyarakat secara langsung. Peneliti dapat mengambil kesimpulan dari sembilan partisipan sebanyak 6 partisipan mengalami stigma. Konsep stigma pertama kali disampaikan oleh Goffman (1963, dalam Bos, (2013) menyatakan stigma dapat dilihat sebagai atribut yang menghubungkan seseorang dengan karakteristik yang tidak diinginkan (stereotip), tidak hanya masalah fisik, melainkan atribut yang menghasilkan ketidaksesuaian sosial dan meluas menjadi perbedaan sosial sehingga mendeskritkan seseorang. Link dan Phelan (2001) lebih luas menjelaskan hubungan antara atribut dan stereotip, stigma adalah ketika ada hubungan interelasi antar masing-masing komponen, komponen pertama orang, dan pelabelan perbedaan setiap orang; komponen kedua adalah budaya, keyakinan, memiliki pengaruh terhadap karakteristik dan stereotipe negatif seseorang, yang ketiga pelabelan sesorang dipisahkan oleh kata "Kami” dan "Mereka"; komponen keempat pelabelan pengalaman seseorang terhadap diskriminasi yang berujung kepada ketidakseimbangan hasil akhir.

\section{Pandangan Terhadap Stigma yang Dihadapi karena ada Anggota Keluarga yang Menderita Kusta}

1. Perasaan selama dan setelah menghadapi stigma karena ada anggota keluarga yang menderita kusta. 
"Sedih dan galau, saya takut orang-orang pada tahu” (P4)2.

2. Pengalaman yang paling menyenangkan dalam menghadapi stigma karena ada anggota keluarga yang menderita kusta.

"yang paling menyenangkan adalah saat atasan suami saya mendukung sepenuhnya kesembuhan suami saya” (P8)

3.Pengalaman yang tidak menyenangkan menghadapi stigma karena ada anggota keluarga yang menderita kusta.

"yang paling tidak menyenangkan saat saya dan istri mengambil obat di Puskesmas, orang-orang memandangi istri saya” (P4)

Kurang mampu beradaptasi terhadap stigma karena ada anggota keluarga yang menderita kusta.

"Yaa mau gimana lagi orang saya sudah menikah dan memiliki anak, masa saya harus tinggalkan suami saya” (P8)

4. Hambatan-hambatan yang ditemui ketika ada anggota keluarga yang menderita kusta khususnya untuk menghadapi stigma masyarakat:

a. Munculnya hambatan berupa perasaan negatif ketika ada anggota keluarga yang menderita kusta khususnya untuk menghadapi stigma masayarakat

"Merasa sedih dan prihatin saja melihat kondisi mamah yang terlihat dijauhi orang-orang terdekatnya" (P9)

b. Saran dan solusi dari petugas kesehatan yang menurut keluarga efektif dalam menghadapi stigma karena ada anggota keluarga yang menderita kusta.

"Adakan penyuluhan agar masyarakat mengerti tentang penyakit kusta agar masyarakat tahu bahwa penyakit ini tidak menakutkan jika di obati” (P4)

5. Harapan keluarga ke depannya terhadap pelaksanaan pendidikan kesehatan kusta terkait pencegahan kecacatan dalam menghilangkan stigma masyarakat.

a. Keluarga ingin mendapatkan pendidikan kesehatan untuk mencegah kecacatan dalam menghilangkan stigma masyarakat. 
"Semoga ada ya...pendidikan kesehatan yang diberikan dapat bermanfaat dan disertai penurunan kejadian kecacatan” (P7)

b. Masyarakat ingin mendapatkan pendidikan kesehatan dalam mencegah kecacatan untuk mengurangi stigma yang dialami keluarga.

“..sebaiknya selain melakukan kunjungan rumah juga dilakukan penyuluhan kesehatan di satu tempat supaya masyarakat juga tahu pentingnya mengetahui apa itu penyakit kusta dan menghilangkan stigma negative masyarakat" (P2)

Keluarga merasakan dampak perubahan kehidupan penderita kusta, terlebih anggota keluarga yang menderita kusta mendapat stigma dari masayarakat. Keluarga akan merasakan berbagai pandangannya dalam menghadapi stigma.

Pandangan keluarga dalam menghadapi stigma pada anggota keluarga mempengaruhi juga kualitas hidup penderita, seperti hasil dari penelitian yang dilakukan oleh Geetha (2015), Das (2015) mengenai dampak penyakit kusta terhadap kualitas hidup didapatkan hasil kualitas hidup yang buruk sebanyak 73,5\%; Das (2015) mengatakan bahwa dampak dari stigma akibat ada yang menderita kusta berupa kurang dihormati sebanyak $24 \%$, orang lain menolak berkunjung ke rumah sebanyak $6 \%$, diskriminasi dalam pekerjaan dan kelompok sosial sebanyak $2 \%$.

Stigma dapat dikurangi dengan melakukan berbagai langkah. Sermrittirong (2014), Adhikari (2013), Raffery Floyd Richard dan Gurungu (2000), mengemukakan langkah mengurangi stigma masyarakat terhadap orang-orang yang terkena kusta hanya dengan memberi mereka pendidikan kesehatan tentang penyakit kusta. Keluarga perlu mengetahui tentang penyakit kusta karena apabila keluarga salah mengetahui tentang informasi penyakit kusta dapat menghambat kemampuan mengatasi dan menyesuaikan diri dengan penderita yang terinfeksi (Ablon, 2002). Batson (2002) menyampaikan bahwa keluargapun dapat menjadi motivasi empati 
untuk anggota yang mengalami stigma, sehingga kelompok dapat memperbaiki sikap terhadap kelompok keseluruhan.

\section{SIMPULAN DAN SARAN}

Penelitian ini menghasilkan tiga tema utama yaitu pemahaman keluarga terhadap perawatan kusta, pengalaman keluarga penderita kusta dalam menghadapi stigma, dan pandangan terhadap stigma yang dihadapi karena ada anggota keluarga menderita kusta. Keluarga kurang mengerti penyakit kusta. Hasil tersebut dilihat dari fenomena bahwa kusta berbahaya dan penderita kusta harus diasingkan serta penularannya dari darah. Namun, sebenarnya penularan kusta membutuhkan waktu yang cukup lama dan harus dengan kontak erat.

Keluarga kurang memahami perawatan kusta seperti pencegahan kecacatan dan perawatan kulitnya. Fenomena yang ada keluarga berpikiran bahwa merawat kusta hanya dengan mematuhi minum obat. Pemahaman tersebut bisa menimbulkan kecacatan pada kulit dan ekstermitas. Selain itu, pada fase awal keluarga merasakan suasana hati/ mood negatif ketika tahu ada anggota keluarga menderita kusta. Keluarga mematuhi minum obat sebagai bentuk perawatan kusta. Perawatan kusta terkadang juga membuat keluarga bosan karena lamanya proses yang harus dijalani ditambah dengan adanya efek samping obat. Keadaan tersebut dikarenakan penyampaian materi yang kurang dari petugas kesehatan dalam pencegahan kecacatan.

Keluarga mendapatkan stigma negatif ketika ada anggota keluarga yang menderita kusta. Stigma negatif dari orang dan lingkungan sekitar berupa isolasi sosial seperti dijauhi dan kontak jarang. Hal tersebut, menyebabkan perubahan suasana hati menjadi sedih/khawatir dan menurun kualitas hidupnya terutama dari aktifitas sehari-hari yang mengalami penurunan. Keluarga menjaga anggota keluarga yang menderita kusta dari stigma masyarakat dengan menutupi kondisi kesehatan tersebut. Perlakuan tersebut sebagai bentuk dukungan keluarga agar penderita tidak 
menjadi malu. Selain itu, keluarga memotivasi dalam perawatan kusta terkait minum obat dan berbagai upaya lainnya.

Masalah atau hambatan yang dialami keluarga dalam menghadapi stigma dari masyarakat ketika penderita mengalami perasaan sedih dan menyendiri. Keluarga harus menguatkan dengan meningkatkan kepercayaan diri klien berupa selalu mendampingi ketika penderita melakukan perawatan. Keluarga berharap agar mendapatkan penyuluhan kesehatan dalam mencegah kecacatan pada penderita kusta. Penyuluhan kesehatan juga sebaiknya terkait perawatan mata, tangan dan kaki baik kulit yang mati rasa maupun gangguan sensorik dan motoriknya.

\section{Saran}

Kepada pihak-pihak yang terkait dengan keluarga yang anggota keluarganya menderita kusta dalam menghadapi stigma masyarakat di Kelurahan Limo Depok Jawa Barat, keluarga hendak selalu memotivasi dan mendukung anggota keluarga yang menderita kusta dalam perawatan kusta dan pencegahan kecacatan dengan mengingatkan untuk minum obat, memantau ketika minum obat sanpai ditelan dan ketika obat habis mengajak ke Puskesmas untuk ambil obat. Selain itu, keluarga memfasilitasi peralatan untuk perawatan kulit, latihan ekstermitas dan mendampingi serta mengajarkan kepada anggota keluarga tersebut. Keluarga juga mendukung anggota keluarganya untuk asertif berkomunikasi ketika timbul perasaan negatif terkait adanya stigma dari lingkungan sekitar.

Perawat Puskesmas hendaknya lebih aktif membuat dan mensosialisasikan program perawatan kusta dan pencegahan kecacatan. Perlunya dibentuk kelompok pendukung bagi penderita kusta dalam menghadapi stigma dari masyarakat sekitar. Selain itu, perlu dilaksanakan gerakan untuk mengenalkan kusta dan mencegahnya dimasyarakat. Penelitian lanjutan yang perlu dikembangkan tentang pola adaptasi keluarga selama merawat penderita kusta dalam mencegah terjadinya kecatatan di masyarakat. Penting dilakukan juga penelitian tentang terapi komunikasi efektif yang dilakukan keluarga terhadap konsep diri penderita kusta. 


\section{UCAPAN TERIMA KASIH}

Peneliti mengucapkan terima kasih atas peran serta semua pihak yang telah mendukung proses berjalannya penelitian ini, terutama kepada Dinas Kesehatan dan KesBangPol Kota Depok, Puskesmas Kelurahan Limo Kota Depok yang telah memberi izin untuk melakukan kegiatan penelitian ini dan dan Warga Kelurahan Limo Kota Depok yang telah bersedia menjadi Partisipan dalam penelitian ini. Ucapan terima kasih peneliti sampaikan kepada KEMENRISTEK DIKTI yang telah memberi dukungan dana melalui DIPA DITLITABMAS Tahun Anggaran 2017, serta Lembaga Penelitain dan Pengabdian Masyarakat UPN "Veteran" Jakarta yang telah mefasilitasi proses kegiatan penelitian ini.

\section{REFERENSI}

Abedi, H et al. (2013). An Exploration of Health, Family and Economic Experiences of leprosy Patients, Iran. Pakistan Journal of Biological Science. Vol 16. p 927

Ablon J. (2002) The nature of stigma and medical conditions. Epilepsy Behaviour Dec;3(6S2) p: 52-59.

Adhikari, Shrestha, Kahlesr, Raut, Chapman (2013). Community Attitudes towards Leprosy Affected Persons in Pokhara Municipality of Western Nepal Jornal Nepal Health Res Counc Vol 11 (25) Sep 2013

Anderson, ET \& McFarlene, J. (2006) Community as Partner: Theory and Practice in Nursing. Ed. 1th. Amazone: Lippincot.

Bainson \& Borne, B (1998). Dimensions and Process of Stigmazation in Leprosy. Leprosy Review. PubMed.gov. US National Library of Medicine National Institute of Health. Dec . 69 (4) p; 342- 350

Batson (2002) Empathy, Attitudes, and Action: Can Feeling for a Member of a Stigmatized Group Motivate One to Help the Group. Downloaded from psp.sagepub.com at Harvard Libraries on February 25, 2015 P: 1656 - 1666 
Bergman (2014). Nursing experience stigma leprosy. Diunduh pada tanggal 20 Oktober 2017. www.diva-portal.org/smash/get/diva2.../FULLTEXT01.pd.

Brouwers, C et al. (2011). Quality of Life, Perceived Stigma, Activity and Participation of People With Leprosy-Related Disabilities in Sout-Eats Nepal. Disability, CBR and Inclusive Development, Vol 22, No. 1

Brunner and Suddarth (2004). Keperawatan Medikal Bedah Jilid 1. Jakarta: EGC

Burns, et al. (2010). Rook's Textbook of Dermatology. Eight Edition. United Kingdom: Wiley-Blackwell.

Burns, N. \& Grove, S.K. (2009). The Practice of Nursing Research: Appraisal, Synthesis, and Generation of Evidence. $6^{\text {th }}$ edition. St. Louis: Saunders Elsevier

Chin, James. (2006). Manual Pemberantasan Penyakit Menular. Jakarta: infomedika Susanto, Tantut. (2013). Perawatan Klien Kusta di Komunitas. Cetakan pertama. Jakarta: CV Trans Info Media.

Creswell, J.W. (2007). Qualitative Inquiry and Research Design. California : SagePublication.Inc.

Crosby (2012). Exploring Stigma, Idnentity Gaps, and Consumption. Disertation Doctor of Philosophy in Busness Adminstration University of Illionis at Urbana-Champaign

Das V. 2006. Stigma, Contagion, Defect: Issues in the Antropology of Public Health.

Degresi. (2005). Ilmu Perilaku Manusia. Jakarta: Rineka Cipta

DinKes Depok (2013). Profil Kesehatan Kota Depok. Depok DinKes

Dogra, S . Narang, T \& Kumar, B. (2013). Leprosy-Evolution of The Path Eradiction. Indian Journal Medical Research No. 137. p: 15 - 35

Ewhrudjakpor, C. (2008). Health Care Provides Knowledge as Correlates of Their Attitudes Towards Leprosy Suffers in Nigeria. Etno Medical. Vo. 2 . No. 2. p: $115-120$

Floyd Richard M, Gurungu S (2000). Stigma reduction through group counseling of persons affected by leprosy- a pilot study. Lepr Rev, 2000; 71: 499-504. 
Geetha, K (2015). Study to Asses the Impact of Leprosy on Qualitu of Life Among Leprosy in Goverment Rehabilitation Home at Paranur. International Journal of Pharmaceutical and Clinical Research 2015 : 7 (6): 466 - 468

Green (2005). Living Stigma: The Impact of Labeling, Stereotiping Separation, Status Loss, and Discrimination in Lives of Individuals with Disabilities and Their Families. Journal Sosiologis Inquiry, Vol. 75. No 2, Mei 2005

Infodatin. (2015). Pusat Data dan Informasi Kementrian Kesehatan RI. Jakarta: Kemenkes

Jacoby, et al. (2005). Stigma of A Chronic Neurological Disorder. Lancet Neurol. Vol 4. P: $171-178$

Joseph, Geetha A \& Rao, S. (1999). Impact of leprosy on the quality of life . Bulletin of the World Health Organization, 1999, 77 (6)

Kemenkes RI.(2013). Informasi Pengendalian Penyakit dan Penyehatan Lingkungan. Jakarta: Derjen Pengendalian Penyalkit dan Penyehatan Lingkungan

Kemenkes. (2014). Buku Saku Pengendalian Penyakit Kusta. Jakarta: Dirjen PMP Kemenkes

Leiningers (2008) Overview of Leininger's Theory of Culture Care Diversity and Universlity. Diunduh dari www.madeline-leininger.com/cc/overview.pdf

Link, Bruce G and Phelan, Jo C. (2001). Conceptualizing Stigma Author. Annual Review of Sociologu Vol. 27: 363 - 385

Luka, Edward Eremugo. (2010). Understanding the Stigma of Leprosy. Sudan: South Sudan Medical Jurnal tahun 2012.

Lusli, M , Zweekhorst. (2014). Dealing with Stigma: Experiences of Persons Affected by Disabilities and Leprosy. Journal Bio Med Research International V 2015, Article ID 261329,

Major, B. \& O’Brien, L (2004). The Social Psychology of Stigma. Annual Review. Departerment of Psychology, University of California, Santa Barbara

Mankar (2011).A Comparative Study of the Quality of Life, Knowledge Attitude and Belief About Leprosy Disease Among Leprosy and Community Members in Shantivan Leprosy Rehabilitation Centre, Nere, Maharsathtra, India. Juornal of Global Infection Diseases 2011 Oct - Dec, 3 (4): 378 - 382 
Mukhlis. 2010. Hubungan Pengetahuan dan Sikap Keluarga dengan Proses penyembuhan pada Penderita Kusta di Kabupaten Bengkalis Riau. Universitas Sumatera Utara: Medan.

Niven.(2008).Psikologi Kesehatan: Pengantar untuk Perawat dan Profesional. Jakarta: EGC

Notoatmodjo, S. (2012). Promosi Kesehatan dan Perilaku Kesehatan. Jakarta: Rineka Cipta

Parker, R \& Aggleton, P. (2002). HIV/AIDS-related Stigma and Discrimination: A Conceptual Framework and an Agenda for Action. Juornal Social Science \& Medicine 57. (2003) p: $13-24$

Polit, DF., Beck, C.T., \& Hungler, B.P. (2001). Essential of Nursing Research: Methods, Appraisal, and Utilization. Philadelphia: Lippincott.

Rafferty, J. (2005). Curing the stigma of leprosy. Leprosy review Journal, 76, 119126.

Sermrittirong, S and Brakel, WHV. (2014). Stigma in Leprosy: concept, Causes and determinants. Journal Lepra Rev. Vol 85, p: $36-47$

Sermrittirong, S and Bunbers, J.F.G (2014) How to Reduce Stigma in Leprosy $-a$ Systematic Literatur Review, Vol. 85 p: $149-157$

Setiadi (2008). Konsep dan Proses Keperawatan Keluarga. Graha Ilmu. Yogyakarta.

Singh. (2012). Psychosocial Aspect of Hansen's Disease (Leprosy). Indian Dermatology Journal. Vol 3. P $166-170$

Sosha, GA. (2012). Employment of Colaizzi's Strategy in Descriptive Phenomenology: A Reflection of Researcher. European Scientific Journal. Nov 2012. Vol 8, N0. 27. ISSN: 1857-7881 (print) e-ISSN 1857 - 7431

Stephen, T; Selvraj, I \& Parameswari, PJ. (2012). Assesment of Knowledge, Attitude and Practice About Leprosy Among Patients and Their Families in a Rural Community in Tamil Nadu. Indian Journal Leprosy. No. 86. P: 7 - 14. Y 2014

Sunyoto, D. (2011). Analisis Regresi dan Uji Hipotesa. Yogyakarta:CAPS 
Sobrinho, R.A.S., Mathias, T.A.F., Gomes, E.A., Lincoln, P.B. (2007). Evaluation in incapacity level of leprosy: a strategy to sensitize and train the nursing team. The Revista Latino-Americana de Enfermagem, 15(6), 1125-1130.

Tohirin. (2011). Metode Penelitian Kualitatif Dalam Pendidikan Dan Bimbingan Konseling. Jakarta: PT RajaGrafindo Persada

Weiss dan Ramakhirsna (2006). Health-related stigma: Rethinking concepts and interventions. Psychology, Health \& Medicine, 11(3) p: 277 - 287

WHO. (2010). Epidemiological Review of Leprosy in The Western Pasisific Region 2008-2010.

Wood, G.L. \& Haber, J. (2006). Nursing Research: Methods and Critical Apraisal for Evidence-Based Practiced. St. Louis: Mosby.

Yuniati, Reni. (2016). Kurang Pemahaman Soal Kusta Pengaruhi Hasil Peneymbuhan. diunduh dari www.actual.com. Tanggal 13 agustus 2017. 